\title{
Accuracy of Measuring Axillary Temperature Using Mercury in Glass Thermometers in Children under Five Years: A Cross Sectional Observational Study
}

\author{
Priyantha Perera1 ${ }^{*}$, Meranthi Fernando', Sachith Meththananda1, Rohini Samaranayake ${ }^{2}$ \\ ${ }^{1}$ Department of Paediatrics, Faculty of Medicine, University of Kelaniya, Kelaniya, Sri Lanka \\ ${ }^{2}$ Department of Tropical Health, Faculty of Medicine, University of Kelaniya, Kelaniya, Sri Lanka \\ Email: ${ }^{*}$ priyanthaprr@gmail.com
}

Received 1 July 2014; revised 19 August 2014; accepted 2 September 2014

Copyright (C) 2014 by authors and Scientific Research Publishing Inc.

This work is licensed under the Creative Commons Attribution International License (CC BY).

http://creativecommons.org/licenses/by/4.0/

\section{(c) (i) Open Access}

\begin{abstract}
Background: Measuring axillary temperature with mercury in glass thermometers is continued in clinical practice though there are many limitations. This is mainly due to convenience and cost. This study was conducted to ascertain the accuracy of measuring axillary temperature with mercury thermometers in preschool children. Methods: Axillary temperature was measured in 250 preschool children using standardized mercury thermometers. Time taken to record the final temperature and its correlates were assessed. Results: Time taken to record the final temperature extended up to six minutes. This duration varied according to age, body mass index and body temperature, but a significant variation was noted only with age. Conclusions: Measuring axillary temperature with mercury thermometers is subjected to error. They need to be replaced with suitable alternatives.
\end{abstract}

Keywords

Axillary Temperature, Mercury, Cross Sectional Study

\section{Background}

Measuring axillary temperature with mercury in glass thermometers is still continued in many clinical settings. This is mainly due to convenience and low cost. It is well accepted that axillary temperature is lower than core

*Corresponding author.

How to cite this paper: Perera, P., Fernando, M., Meththananda, S. and Samaranayake, R. (2014) Accuracy of Measuring Axillary Temperature Using Mercury in Glass Thermometers in Children under Five Years: A Cross Sectional Observational Study. Health, 6, 2115-2120. http://dx.doi.org/10.4236/health.2014.616245 
temperature and there is no universally accepted equation to determine the core temperature from axillary temperature [1] [2]. Evidence in medical literature is divided on the accuracy of predicting core temperature with axillary temperature. Some studies have shown poor correlation between axillary and rectal temperature [3], while others have shown a good correlation [4]. In addition, there is no consensus on optimum placement time of the thermometer in axilla during axillary temperature measurement [2]. Although measuring rectal temperature is the most accurate method of taking the body temperature [5], it is not measured routinely due to practical difficulties. Measuring oral temperature is reasonably accurate, but sterility issue and the potential injury hazards in small children are major limitations to its use. Measuring trans-tympanic temperature is quick, but the equipment is expensive and not freely available. Due to concerns over mercury pollution many countries have changed to digital electronic thermometers. In Sri Lanka, digital thermometers are used in some private hospitals, but most of the government hospitals and households use mercury in glass thermometers.

Electronic thermometers have the facility to indicate when final temperature is recorded, which is not available mercury in glass thermometers. Sick, small children often resist keeping a thermometer in the axilla for long and leads to under recording of the temperature. Optimum control of fever depends on accurate temperature measurement. A study in adults has shown that axillary temperature reading varies with age and race [6], but no such studies are available in children. This study was carried out to ascertain the appropriateness of measuring axillary temperature with mercury in glass thermometers in children less than five years. For this purpose we assessed the optimum placement time for mercury in glass thermometer in children under five years and whether this duration varied with parameters like age, sex, body mass index and body temperature.

Our study highlights the inaccuracy of measuring axillary temperature with mercury thermometers and importance of replacing them with suitable alternatives.

\section{Methods}

A descriptive cross sectional study was carried out at the University Paediatric Unit of Colombo North Teaching Hospital (CNTH), Sri Lanka, during January 2013 and February 2013.

\subsection{Subject Selection}

A preliminary study at the CNTH revealed that axillary temperature is measured in all wards using mercury in glass thermometers, irrespective of the age. Duration of the placement time slightly varied between units, but most of the wards kept the thermometer for three minutes. A sample size of 249 children was required to estimate a mean duration of 3 minutes, with a standard deviation of 1 minute and an alfa error of 0.125 . Therefore, fifty children from each age category from birth to 5 years were recruited. Every second child under 5 years of age admitted to the university Paediatric unit was considered for recruitment. Once 50 children from a particular age category were recruited, no further children from that age category were recruited. Children were recruited irrespective of having fever. Any child who was too ill or uncooperative was replaced by another. Informed written consent was obtained from mother/guardian to include the child in the study.

\subsection{Data Collection}

A set of mercury in glass clinical thermometers were immersed for 10 minutes, in a water bath maintained at $98^{\circ} \mathrm{F}$. Five thermometers with correct readings were selected for the study. They were rechecked weekly during the study and remained accurate.

Age was recorded in completed years. Weight was measured to the second decimal in kilograms using a beam balance scale. Height of children above 2 years was measured using a stadiometer and an infantometer was used for children under 2 years. Measurements were taken in centimetres to the first decimal.

Before measuring the temperature mercury column was set at $96^{\circ} \mathrm{F}$. The bulb of the thermometer was placed within the axillary fossa, with arm firmly adducted over it ensuring good contact between skin and thermometer. Readings were recorded every 30 seconds, while the thermometer remained in the axilla. Readings were taken until three similar consecutive readings were obtained. Thermometers were cleaned with surgical spirit in between patients to avoid cross infections. Temperature measurement was terminated if a child got irritable and disturbed during the process and was replaced with a child from same age category. A total of 21 children had to be replaced. 
Data collection was done by two medical graduates who were trained and supervised by the first investigator.

\subsection{Permission to Conduct the Study}

Permission to conduct the study was obtained from the Director of NCTH. Ethical approval was obtained from research and ethics committee of the Faculty of Medicine, University of Kelaniya.

\subsection{Analysis of Data}

Descriptive statistics and frequency tabulations were generated using Statistical Package for Social Sciences, version 16. Independent student t-test and ANOVA test were used to compare means.

\section{Results}

Of the 250 children who completed temperature recording, 131 (52.4\%) were boys. The time taken to record the final temperature ranged from 30 seconds to 6 minutes. The median duration was of 3 minutes and inter quartile range (IQR) of 2 to 3.5 minutes (Table 1 ).

There was no significant difference in the duration needed to record the final temperature for boys $(2.98 \pm 1.2$ minutes) and girls (2.94 \pm 1.2 minutes). A significant variation was observed between time taken to record final temperature and age $(p=0.03)$. This is illustrated in Figure 1.

The distribution of anthropometric measurements of the study sample is depicted in Table 2. Duration taken to achieve final temperature decreased with increasing BMI, but this was not statistically significant $(p=0.68)$. Figure 2 illustrate the association between mean duration taken for temperature stabilization and body mass index.

Final temperature recorded from children varied from $96.2^{\circ} \mathrm{F}-103.7^{\circ} \mathrm{F}$. The median of the final temperature recorded was $98.4^{\circ} \mathrm{F}$ (IQR: 97.8 to 99.2). Table 3 depicts statistical characteristics of the final temperature recorded. Duration taken to record the final temperature increased with increasing body temperature, but the difference was not statistically significant. The relationship between time taken to record the final temperature and final recorded temperature is depicted in Table 4.

Table 1. Distribution of time taken to record final temperature.

\begin{tabular}{cc}
\hline Time (Minutes) & Frequency \\
\hline .5 & $01(0.4 \%)$ \\
1.0 & $13(5.2 \%)$ \\
1.5 & $25(10.0 \%)$ \\
2.0 & $35(14.0 \%)$ \\
2.5 & $46(18.4 \%)$ \\
3.0 & $30(12.0 \%)$ \\
3.5 & $42(16.8 \%)$ \\
4.0 & $28(11.2 \%)$ \\
4.5 & $14(5.6 \%)$ \\
5.0 & $11(4.4 \%)$ \\
5.5 & $03(1.2 \%)$ \\
6.0 & $02(0.8 \%)$ \\
Total & $250(100 \%)$ \\
\hline
\end{tabular}


Table 2. Distribution of anthropometric indices of study sample $(n=250)$.

\begin{tabular}{ccccc}
\hline Category & Weight for age $\%$ & Height for age $\%$ & Weight for height \% & BMI \% \\
\hline More than 2 SD & 4.9 & 9.4 & 4.5 & 6.9 \\
Between +2 SD to -2 SD & 69.8 & 78.8 & 63.1 & 62.4 \\
Between -2 SD to -3 SD & 18.0 & 5.3 & 13.9 & 13.1 \\
Below -3 SD & 7.3 & 6.5 & 18.4 & 17.6 \\
Total & 100.0 & 100.0 & 100.0 & 100.0 \\
\hline
\end{tabular}

Table 3. Distribution of final temperature recorded.

\begin{tabular}{cc}
\hline Statistics & Temperature $\left({ }^{\circ} \mathrm{F}\right)$ \\
Mean & 98.68 \\
SD & 1.3 \\
Minimum & 96.2 \\
First quartile & 97.8 \\
Median & 98.4 \\
Third quartile & 99.2 \\
\hline
\end{tabular}

Table 4. Relationship between mean duration to record final temperature and final temperature.

\begin{tabular}{cccc}
\hline Final temperature & Number of children & Mean duration to record final temperature & Standard deviation \\
\hline $97-97.9$ & 66 & 2.6 & 1.1 \\
$98-98.9$ & 107 & 2.9 & 1.1 \\
$99-99.9$ & 39 & 3.4 & 1.4 \\
$100-100.9$ & 15 & 3.3 & 1.2 \\
$101-101.9$ & 07 & 3.7 & 1.5 \\
$102-102.9$ & 03 & 3.7 & 1.2 \\
$103-103.9$ & 05 & 3.0 & 1.0 \\
\hline
\end{tabular}

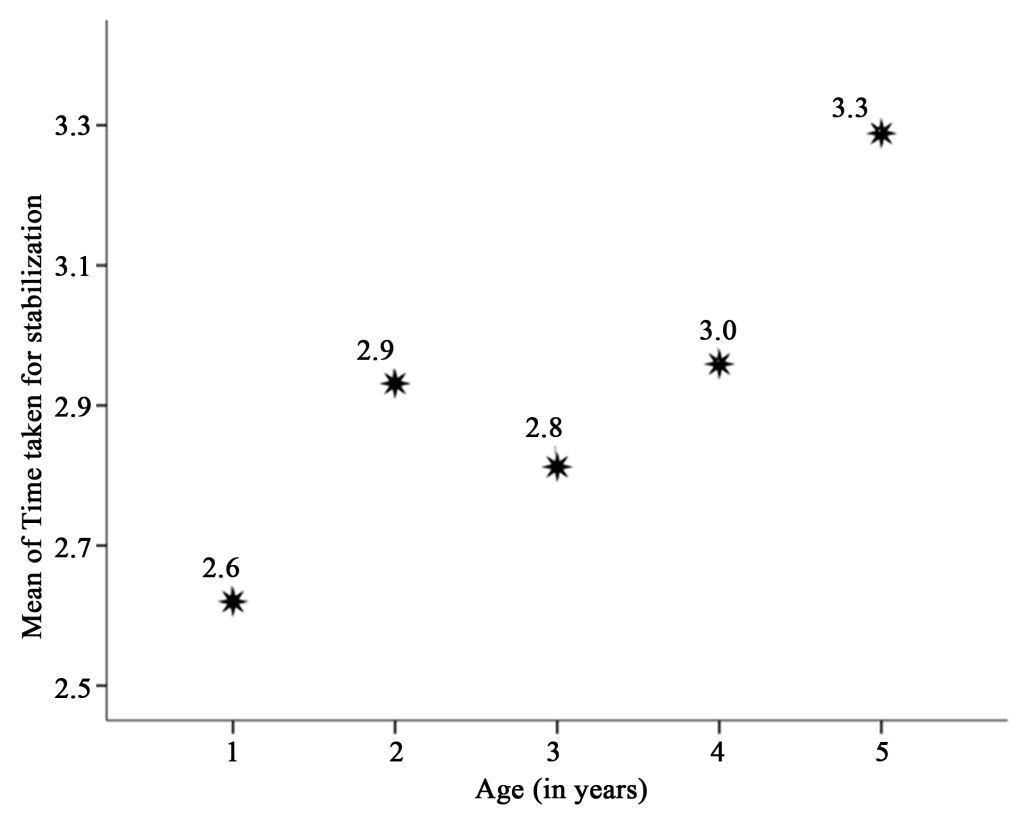

Figure 1. Relationship between age and time taken to record final temperature. 


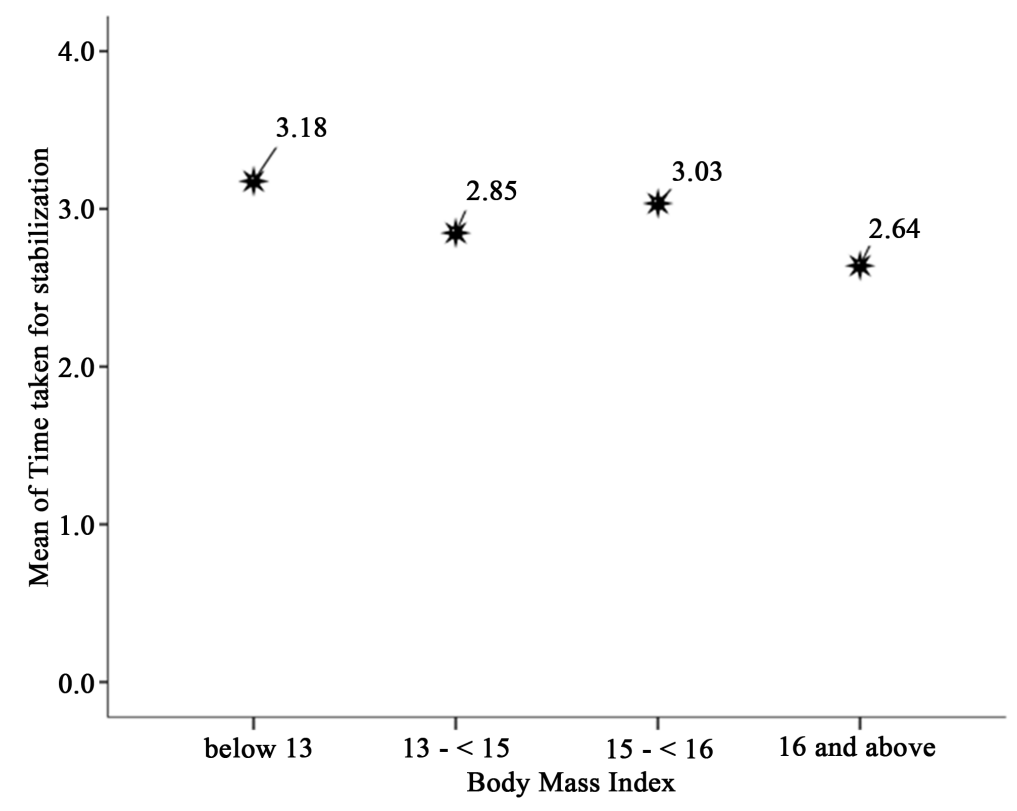

Figure 2. Relationship between body mass index and time taken to record final temperature.

\section{Discussion}

Accurate temperature measurement is vital for optimum control of fever, especially in critically ill patients [7]. Children are often non-cooperative during examination and temperature recording is difficult. Axillary temperature measurement is preferred in children because of the convenience. Rectal temperature measurement is unpleasant and oral temperature measurement is not possible in preschool children. Trans-tympanic measurement is easy but the equipment needed is not available in most clinical settings. Main issue involved in measuring axillary temperature with a mercury thermometer is to decide when to remove the thermometer. We have observed mothers removing the thermometer very quickly as child struggles. According to previous studies, duration to place the thermometer in axilla to reach the final recording varies from few seconds to 15 minutes [9] [10]. In our study though the median was three minutes, time to achieve a final recording extended up to six minutes. These figures indicate measuring axillary temperature with mercury thermometers is subjected to error.

Mercury thermometers work by the physical principle of expansion with raising temperature. Therefore the time taken to record the final temperature will depend on rate of transfer of heat from the skin to the bulb of thermometer. Mulley et al have demonstrated that in hemiplegic patients axillary temperatures of normal sides and affected sides are significantly different [11]. A study in adults has shown that temperature readings vary with age and race [6], but no such reported studies in children.

According to our study, out of age, sex and BMI only age had a significant influence on the time to record the final temperature. Interestingly the body temperature did not have a significant influence on the time taken to record final temperature. With increasing body temperature one would expect a longer duration to record the final temperature. However, as the rate of energy transfer depends on the temperature difference between the bulb and the skin, the duration to record final temperature has not changed significantly with increased body temperature.

In a report to the congress, US environment agency has expressed concern regarding mercury released to the environment through broken thermometers and other medical equipment [12]. Though metallic mercury is nontoxic, it is converted to highly toxic methyl mercury by microorganisms, which can find its way in to human beings. Potential environmental hazards and unreliability of the readings means it is time to remove mercury thermometers from clinical practice.

Electronic digital thermometers and trans-tympanic thermometers do not contain mercury, no risk of injury and better tolerated by children. More importantly, they have the ability to indicate when final temperature is recorded. 


\section{Conclusion}

Using mercury thermometers to measure axillary temperature in children is unreliable because the reading depends on the placement time. Optimum placement time can extend up to six minutes and the placement time for a given individual cannot be predicted because it will vary according to the age.

\section{Competing Interests}

All authors declare there are no competing interests.

\section{Authors' Contribution}

PJP was involved in planning, supervising data collection, data analysis and preparing the manuscript. MPF, TW and RS were involved in planning, data analysis and preparing the manuscript

\section{Author Information}

PJP is a senior lecturer in Paediatrics, attached to the University of Kelaniya and also works as a honorary consultant Paediatrician at Teaching Hospital Ragama, Sri Lanka. MPF is a lecturer in Paediatrics, attached to University of Kelaniya. TW is a lecturer in Physiology, attached to University of Kelaniya. RS is a research assistant attached to tropical Medicine department of faculty of Medicine, University of Kelaniya.

\section{Acknowledgements}

We would like to thank all children and their mothers who participated in the study. We are also grateful to nursing staff of university Paediatric unit, Teaching Hospital Ragama for their cooperation.

\section{References}

[1] Craig, J.V., Lancaster, G.A., Willianson, P.R. and Smyth, R.L. (2000) Temperature Measured at the Axilla Compared with Rectum in Children and Young People: Systematic Review. BMJ, 320, 1174-1178. http://dx.doi.org/10.1136/bmj.320.7243.1174

[2] Lodha, R., Mukherji, N., Pandey, R.M. and Jain, Y. (2000) Is Axillary Temperature an Appropriate Surrogate for Core Temperature? The Indian Journal of Pediatrics, 67, 571-574. http://dx.doi.org/10.1007/BF02758482

[3] Kara, A., Devrim, I., Ali Bülent, C., Çelik, F., Tezer, H., Uludag, A.K. and Seçmeer, G. (2009) Is the Axilla the Right Site for Temperature Measurement in Children by Chemical Thermometer? The Turkish Journal of Pediatrics, 51, 325-327.

[4] Chaturvedi, D., Vilhekar, K.Y., Chaturvedi, P. and Bharambe, M.S. (2004) Comparison of Axillary Temperature with Rectal or Oral Temperature and Determination of Optimal Placement Time in Children. The Indian Journal of Pediatrics, 41, 600-603.

[5] Morley, C.J., Hewson, P.H., Thornton, A.J. and Cole, T.J. (1992) Axillary and Rectal Temperature Measurements in Infants. Archives of Disease in Childhood, 67, 122-125. http://dx.doi.org/10.1136/adc.67.1.122

[6] Smith, L.S. (2003) Reexaminning Age, Race, Site, and Thermometer Type as Variables Affecting Temperature Measurement in Adults-A Comparison Study. BMC Nursing, 2, 1. www.biomedcentral.com/1472-6955/2/1

[7] Lawson, L., Elizabeth, J.B., Isabelle, B., et al. (2007) Accuracy and Precision of Noninvasive Temperature Measurement in Adult Intensive Care Patients. American Journal of Critical Care, 16, 485-496.

[8] Nicholas, G.A., Ruskin, M.M., Glob, B.A.K. and Kelly, W.H. (1966) Oral, Axillary, Rectal Temperature Determinations and Relationships. Nursing Research, 15, 307.

[9] Mayfield, S.R., Bhatia, J., Nakamura, K.T., Rois, G.R. and Bell, E.F. (1984) Temperature Measurement in Term and Preterm Neonates. The Journal of Pediatrics, 104, 271-275. http://dx.doi.org/10.1016/S0022-3476(84)81011-2

[10] Asadi-Pooya, A.A. and Kashef (2006) Accuracy of Axillary Temperature Compared with Rectal Temperature in Sick Children. Kuwait Medical Journal, 38, 25-27.

[11] Mulley, G. (1980) Axillary Temperature Differences in Hemiplegia. Postgraduate Medical Journal, 56, $248-249$. http://dx.doi.org/10.1136/pgmj.56.654.248

[12] United States Environment Protection Agency (1997) Mercury Study Report to Congress. 
Scientific Research Publishing (SCIRP) is one of the largest Open Access journal publishers. It is currently publishing more than 200 open access, online, peer-reviewed journals covering a wide range of academic disciplines. SCIRP serves the worldwide academic communities and contributes to the progress and application of science with its publication.

Other selected journals from SCIRP are listed as below. Submit your manuscript to us via either submit@scirp.org or Online Submission Portal.
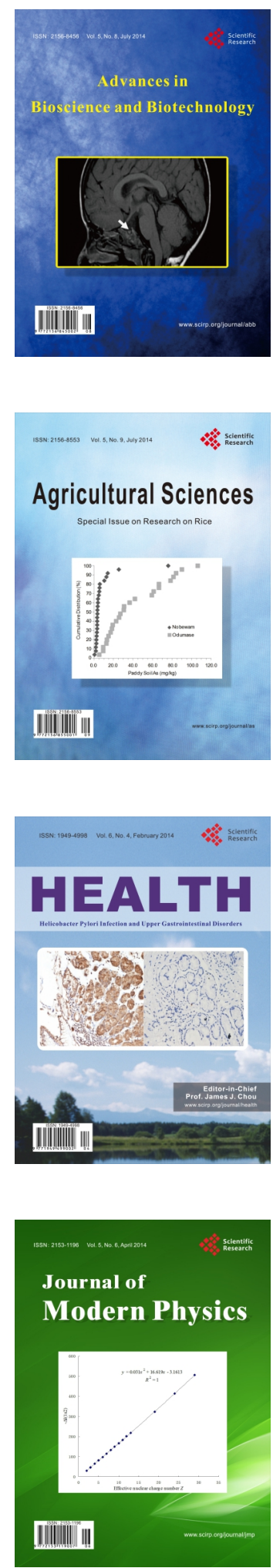
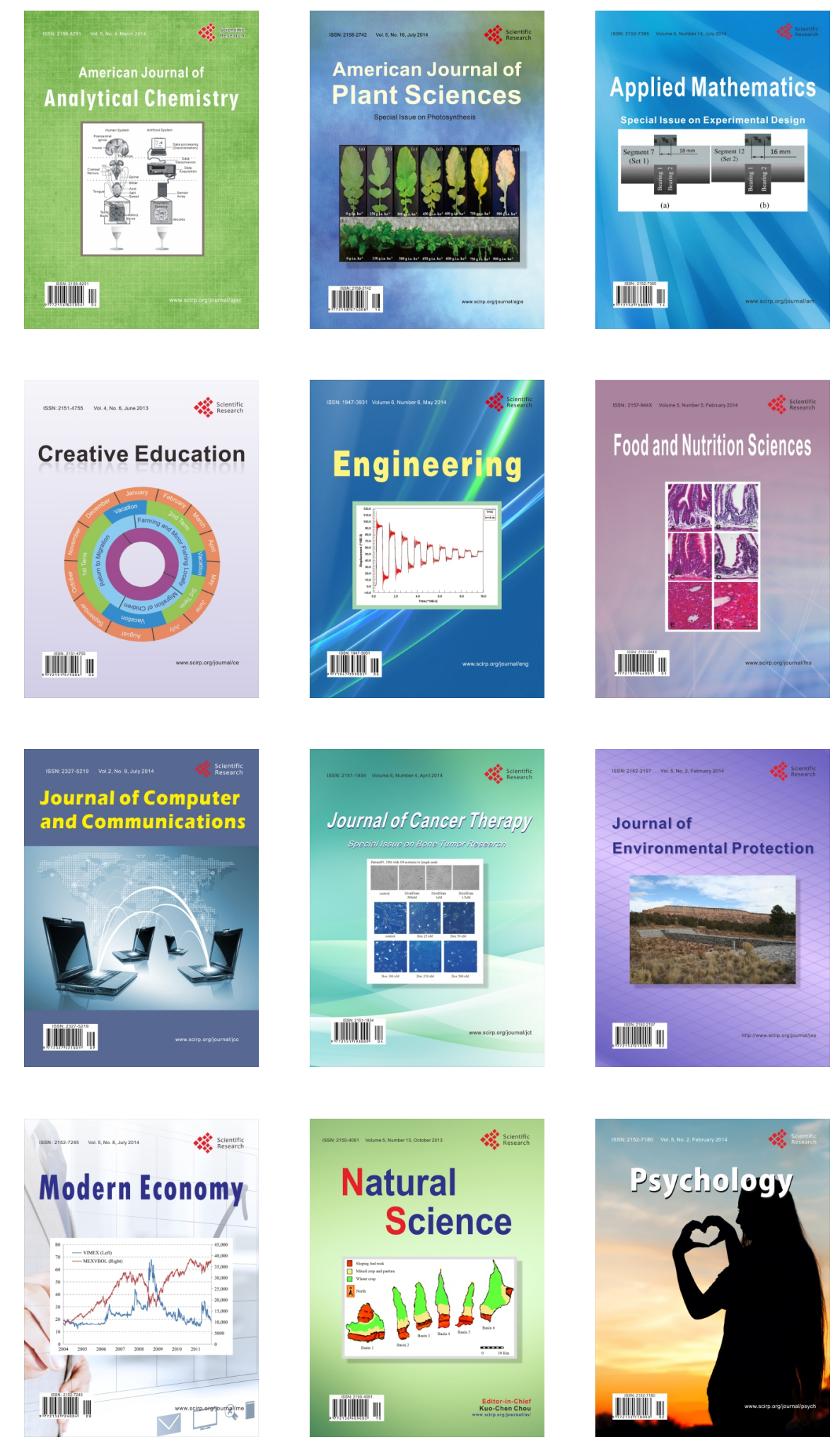